\title{
Plant-derived Saponins: A Review of their Surfactant Properties and Applications
}

\author{
Summi Rai 1, Eliza A. Siwakoti ${ }^{2}$, Ananda Kafle ${ }^{3}$, Hari Prasad Devkota 4,*, Ajaya Bhattarai 1,* \\ 1 Department of Chemistry, Mahendra Morang Adarsh Multiple Campus, Tribhuvan University, Biratnagar, \\ Nepal; sumierai73@gmail.com \\ 2 Department of Botany, Mahendra Morang Adarsh Multiple Campus, Tribhuvan University, Biratnagar, \\ Nepal; elizaacharyas1234@gmail.com \\ 3 Institute for Materials Chemistry and Engineering, Kyushu University, Fukuoka 819 0395, Japan; anan- \\ dakafle@gmail.com \\ 4 Graduate School of Pharmaceutical Sciences, Kumamoto university, 5-1 Oe-honmachi, Kumamoto 862-0973, \\ Japan \\ * Correspondence: devkotah@kumamoto-u.ac.jp (H.P.D.), ajaya.bhattarai@mmamc.tu.edu.np (A.B.)
}

\begin{abstract}
Increasing environmental concern and consumer demand for natural, sustainable and eco-friendly products have prompted the replacement of synthetic surfactants with their natural plant-based alternatives. Saponins are the plant based natural surfactants characterized by their foam forming properties in aqueous solution. Their natural origin makes them eco-friendly, biodegradable and non-toxic. Further, they possess better physicochemical properties than the synthetic ones. They are also reported to exhibit a lot of useful biological activities such as anti-cancer, antifungal, anti-inflammatory, antimicrobial, antioxidant and cholesterol-lowering properties. Because of their excellent surface activity, biological activities and wide distribution in nature, saponin rich plants deserve deeper insight as a sustainable source of natural surfactants as they possess the potential to replace toxic synthetic surfactants abundant today. This review article is intended to provide a brief overview on the saponins with a special notion on their surface-active properties. It encourages further studies on development of commercial formulations based on saponins for the complete replacement of the synthetic counter parts, making better use of plants sources thereby contributing to global agenda of green environment.
\end{abstract}

Keywords: Natural surfactants; plants; saponins; eco-friendly; synthetic surfactants.

\section{Introduction}

Environmental pollution is one of the great existential global burdens that has degraded the earth's ecosystem and threatened the lives on earth [1]. With increasing environmental concern, there is a trend of replacing synthetic products with their natural equivalents all across the globe $[2,3,4]$. However, it is a grand challenge of the present generation, not merely due to the scarcity of their availability, but due to their high extraction and processing costs compared to the manufacturing of their synthetic equivalents [5]. Along these lines are a group of synthetic chemical compounds known as surfactants. Surfactants are usually known as the major components of household detergents and cleaning products [6] that can reduce the surface tension of water, thereby enhancing its cleansing ability. Besides, they also find their application as emulsifiers, wetting agents, dispersants and foaming agents in cosmetics, personal care products, food and paper processing, oilfield field chemicals, agricultural chemicals, pharmaceuticals, textiles, emulsion polymerization and many other markets as well [7], [8]. Owing to their widespread application in diverse field, surfactants are among the most produced industrial chemicals. This far huge variety of surfactants has been synthesized to meet the demand of the consumer. These synthetic surfactants are largely based on petrochemical raw materials [9]. Because of their petrochemical origin, they are mainly toxic and non-biodegradable, causing many detrimental effects on the environment $[10,11]$. 
Nevertheless, we have natural surfactants that stand out as eco-friendly and sustainable alternatives to their synthetic equivalents. Natural surfactants, as the name suggests, are of natural origin i.e. derived directly from nature either from plants or animal sources [11, 12]. Based on their origin, natural surfactants are broadly classified into two categories: (i) plant-derived natural surfactants and (ii) natural surfactants produced by the fermentation of natural substrates like alkanes, oil, sugars and wastes in the presence of microbes such as bacteria or yeast, usually termed bio-surfactants [5][12]. The production of bio-surfactants is limited due to the high cost of production and threat to food security as it uses carbon sources [13]. Providently, plants remain as largely untapped sources of natural surfactants. Therefore, more research is to be carried out particularly in exploration, extraction and isolation of natural surfactants from plants distributed widely in nature. Plants synthesize an unlimited number of bioactive chemical substances [14] that are less toxic and biodegradable than synthetic ones. Among the various bioactive chemical compounds derived from plants, saponins are the ones that exhibit surfactant properties [15]. They got their name "saponins" derived from Latin word sapo, which means soap as they form soapy lather when agitated with water [16]. Their natural origin makes them eco-friendly, biodegradable and non-toxic which are of utmost importance from environmental and health perspectives. Along with being bioactive, previous works have documented the better physicochemical properties of saponins than the synthetic ones. Because of the excellent physicochemical and biological properties, saponin-rich plants deserve a deeper insight as a source of natural surfactants important not only for research but also for their commercial prospects [17].

In this review, we provide a brief overview of the molecular and physicochemical properties of plant-based natural surfactant, saponins emphasizing their ability to enhance surface activity and form micelles like conventional surfactants. These properties make them a potential substitute to synthetic surfactants in a vast array of practical applications. Here, we also discuss the new opportunities, prospects, and the potential challenges associated with the development of saponin-based commercial formulations.

\section{2. Molecular Structures of Saponins}

Structurally, saponins are naturally occurring amphiphilic glycosides containing hydrophilic (polar) glycone moieties (sugars) linked with hydrophobic (non-polar) aglycones moieties also known as sapogenins [18]. Based on the aglycone counterpart of saponins, they are classified as (i) steroidal and (ii) triterpenoid saponins [19]. The difference between these two classes is that the steroidal saponins are molecules with $27 \mathrm{C}$-atoms whereas the triterpenoid saponins are molecules with $30 \mathrm{C}$-atoms [20]. Triterpenoid saponins are further subcategorized into (i) Oleanane saponins (eg. Sapindus mukurossi, Camellia oleifera, etc.) (ii) Ursolic and Oleanane saponin (eg. Ilex Paragariensis) and(iii) Dammarane saponins (e.g. Panax gingseng). Steroid saponins are also either furostanol type or spirostanol type [21]. Saponins from Solanaceae family have steroidal glycoalkaloids as aglycone back bone [22]. Based on the number of sugar units (glycone) attached to the aglycone of the saponins are classified as (i) monodesmosidic saponins: a single sugar unit attached to carbon-3. (ii) bidesmosidic saponins: two sugar units, one attached to C-3 and others attached to C-26 or C-28. (iii) Tridesmosidic saponins: three sugar units attached to the aglycone, but are rarely found [23], [24]. The sugar units attached to the aglycone may be linear chains or branched chains, which are mainly D-glucose (Glc), D-galactose (Gal), L-arabinose (Ara), L-rhamnose (Rha), D-xylose (Xyl), D-fructose (Fuc) or D-glucuronic acid (GlcA) [25],[26]. A photograph of fruit of Sapindus mukurossi and its main saponins and aglycone are presented in Figure 1. 


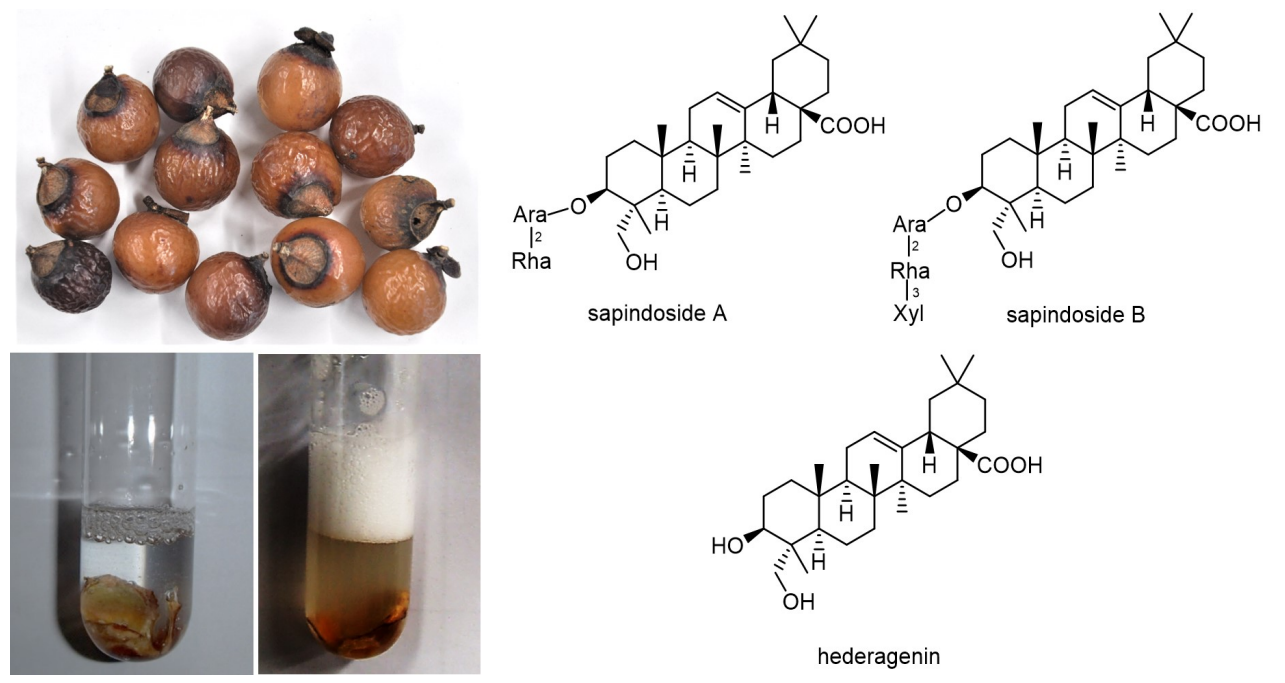

Figure 1. Photograph of Sapindus mukurossi fruits, a foam formed after shaking paricarps in water, and structures of saponins and their aglycone, hederagenin.

\section{Sources of saponins}

Saponins are the diverse group of secondary metabolites predominantly distributed in more than 100 families of vascular plants including some marine sources (starfish, sea cucumber, etc). Dicotyledonous plants are the major sources of triterpenoid saponins (families such as; Leguminosae, Araliaceae and Caryophyllaceae) while monocotyledonous plants (families such as Liliaceae, Dioscoreaceae and Agavaceae) are the major sources of steroidal saponins [27][28]. Some of the saponin rich plants traditionally used as natural surfactants and other plants rich in saponin that could be a potential source of natural surfactant have been presented in Table 1 and Table 2, respectively.

Table 1: List of saponin rich plants traditionally used as natural surfactants for washing purpose.

\begin{tabular}{|c|c|c|c|c|}
\hline Scientific Name & Common Name & $\begin{array}{l}\text { Saponin } \\
\text { Type }\end{array}$ & Parts Used & References \\
\hline Acacia concinna & Shikakai & Triterpene & Pods and bark & {$[18,30]$} \\
\hline Acanthophyllum squarrosum & & Triterpene & $\begin{array}{l}\text { Roots, grooves, } \\
\text { shell and white } \\
\text { interior. }\end{array}$ & {$[31,32]$} \\
\hline Albizia procera & Seto Siris & Triterpene & Leaves & [29] \\
\hline Chlorogalum pomeridia & Soap root & Triterpene & Root & \multirow{5}{*}[31,33,34]{} \\
\hline Quillaja saponaria & Soap bark & Triterpene & Inner bark & \\
\hline Sapindus mukurossi & Soap nut & Triterpene & Fruit pericarp & \\
\hline Saponaria officinalis & Soapwort & Triterpene & Roots and Leaves & \\
\hline Sapindus saponaria & Soap berry & Triterpene & Seed & \\
\hline
\end{tabular}


Table 2: List of saponin rich plants that could be a potential source of natural surfactants.

\begin{tabular}{|c|c|c|c|}
\hline Scientific Name & Common Name & Parts Used & References \\
\hline Acorus gramineus & $\begin{array}{l}\text { Grass-leaved Sweet Rush, Japa- } \\
\text { nese Sweet Flag, Dwarf Sweet } \\
\text { Flag }\end{array}$ & Leaves & [17] \\
\hline Aesculus assamica & Horse Chestnut & Leaves & {$[17]$} \\
\hline Aesculus indica & $\begin{array}{l}\text { Indian horse chestnut, Kanor, } \\
\text { Barkhor }\end{array}$ & Fruits & [34] \\
\hline Agave americana & $\begin{array}{l}\text { Agave, Bara Kunwar, Kantala, } \\
\text { Ran Ban }\end{array}$ & Leaves & {$[34]$} \\
\hline Agave offoyana & Maguey & Flowers & {$[21,29]$} \\
\hline Agave sislana & Sisal & Leaves & {$[33,37]$} \\
\hline Allium nigrum & Ornamental onion & Roots and Leaves & {$[23]$} \\
\hline Asparagus adscendens & Sansban, Saunspali & Fruits and roots & {$[34]$} \\
\hline Asparagus racemosus & Shatavari & Roots & {$[34]$} \\
\hline Balanites aegyptiaca & Heglig & Fruits, seeds and bark & {$[33,38]$} \\
\hline Beaucarnea recurvata & Ponytail palm & Leaves & {$[23]$} \\
\hline Bupleurum chinense & Bei Chai $\mathrm{Hu}$ & Roots & {$[23]$} \\
\hline Camelia chekiangoleosa & & Seed & {$[38]$} \\
\hline Camelia japonica & & Leaf and stem & {$[38]$} \\
\hline Camellia oleifera & Tea & Seeds & {$[3]$} \\
\hline Camellia reticulata & & Seeds & {$[38]$} \\
\hline Camellia sinensis & Tea & $\begin{array}{l}\text { Root, seeds, leaves } \\
\text { and flowers }\end{array}$ & {$[35,39]$} \\
\hline Caryocar villosum & Piquia & Stems & {$[23]$} \\
\hline Chiococca alba & West Indian milkberry & Roots & {$[23]$} \\
\hline $\begin{array}{l}\text { Chlorogalum pomeridi- } \\
\text { anum }\end{array}$ & Soap plant & Bulbs & {$[32]$} \\
\hline $\begin{array}{l}\text { Chlorophytum } \\
\text { borivilianum }\end{array}$ & Safed musli & Leaves & {$[34]$} \\
\hline Cicer arietinum & Chickpeas & Seeds & [39] \\
\hline Cissus modeccoides & & Leaves and stems & {$[17]$} \\
\hline Cissus repen & & Stems & {$[17]$} \\
\hline Digitalis Ianata & Woolly foxglove & Leaves & {$[32]$} \\
\hline Digitalis purpurea & Purple foxglove & Leaves and seeds & {$[32]$} \\
\hline Dillenia parviflor & & Fruits & {$[17]$} \\
\hline Discorea composite & Yams & Rhizomes and roots & {$[32]$} \\
\hline Garcinia sp. & Yellow Mangosteen & Fruits & {$[17]$} \\
\hline Garuga pinnata Roxb & Garuga & Leaves & [17] \\
\hline Glinus lotoides & Soap Jacob & $\begin{array}{l}\text { Roots, leaves and } \\
\text { seeds }\end{array}$ & {$[32]$} \\
\hline Glycine max & Soya bean & Sprouts and seeds & {$[33,40]$} \\
\hline Gypsophilla paniculata & Baby's breath & Roots & {$[32]$} \\
\hline Harpullia austrocaledonica & & Bark & {$[23]$} \\
\hline Ilex paraguariensis & Mate & Fruits & {$[40]$} \\
\hline Lens culinaris & Lentils & Seeds & [39] \\
\hline Lonicera japonica & Honeysuckle & Leaves & {$[34]$} \\
\hline Luffa cylindrica & Sponge Gourd & Fruits & {$[17]$} \\
\hline Microcos tomentosa & & Leaves & [17] \\
\hline Momordica charantia & Bitter melon & Fruits and stems & {$[23]$} \\
\hline Oryza sativa & Asian rice & Peels & [17] \\
\hline Oxalis corniculata & Creeping wood sorrel & Leaves and stems & [17] \\
\hline Phaseolus vulgaris & Haricot bean & Seeds & [39] \\
\hline
\end{tabular}




\begin{tabular}{|l|l|l|l|}
\hline Phaseolus vulgaris & Kidney beans & Seeds & {$[39]$} \\
\hline Pisum sativum & Green pea & Seeds & {$[39]$} \\
\hline Salix tetrasperma & Indian willow & Pericarps & \\
\hline Sapindus rarak & & Fruits & {$[17]$} \\
\hline Sapindus trifoliatus & & Pericarp & {$[12]$} \\
\hline Sesamun orientale & Beniseed & Leaves & {$[17]$} \\
\hline Silene inflata Sm. & Bigru & Roots & {$[34]$} \\
\hline Silphium asteriscus & Starry rosinweed & Leaves and stems & {$[23]$} \\
\hline Solanum xanthocarpum & Yellow-berried Nightshade & Fruits and stems & {$[23]$} \\
\hline Tribulus terrestris & Puncture vine & Fruits & {$[23]$} \\
\hline $\begin{array}{l}\text { Trigonella faenum grae- } \\
\text { cum }\end{array}$ & Fenugreek & Seeds and leaves & {$[32]$} \\
\hline Vigna radiata & Mung bean & Seeds & {$[39]$} \\
\hline Yucca schidigera & Yucca & Bark & {$[23]$} \\
\hline Zephyranthes cainata & Pink rain lily & Bulb & {$[4]$} \\
\hline Ziziphus joazeiro & Juá & Bark & {$[36]$} \\
\hline
\end{tabular}

Saponins are generally found in roots, leaf, fruit, pericarp, flowers and seeds of a plant [32]. Saponins extracted from a plant are often a blend of various types of saponin. [35]. The composition and concentration of saponin extracts not only vary in different plants but also on different parts of the same plant. Saponin composition and content is also strongly affected by the environmental factors during the development of plant and on the extraction procedure [21,32]. In general, there are two techniques for the extraction of saponin namely: conventional and green technology. Conventional techniques include maceration, soxhlet extraction and reflux extraction. Green technology includes ultrasound assisted extraction, microwave assisted extraction and accelerated solvent extraction. There has been a remarkable development in their extraction methods. The earlier research groups followed the conventional methods. But nowadays, the green synthesis methods have gained popularity because of their greater efficiency and eco-compatibility [41].

\section{Surfactant properties of saponins and their potential applications}

The surfactant properties of saponins in aqueous solutions can be attributed to its amphiphilic structure which is a combination of lipophilic non-polar aglycone and hydrophilic polar glycone moieties [20]. This structural feature of a saponin molecule resembles that of a synthetic surfactant molecule. A typical surfactant molecule also has an amphiphilic structure with a water-soluble (hydrophilic) head group attached to a water-insoluble (hydrophobic) tail group. The hydrophilic part is a highly polar group (ionic or non-ionic) while the hydrophobic part is a long chain hydrocarbon (aliphatic, aromatic or the mixtures of both) [42]. Based on the charge on the hydrophilic polar head group, surfactants are classified as: (i) Anionic Surfactants with a hydrophilic head of the anionic functional group (ii) Cationic Surfactants with a hydrophilic head of the cationic functional group (iii) Zwitter-ionic Surfactants with a hydrophilic head made of both anionic and cationic functional groups and (iv) Nonionic Surfactants with uncharged hydrophilic head [43] . In case of a saponin molecule, the hydrophilic part is made up of water-soluble sugar chains while the hydrophobic part may be water insoluble steroid or triterpenoid [26]. With this combination, saponins belongs to a class of non-ionic surfactants [11] and hence exhibit various surfactant relevant properties (surface activity, micellization, foaming, detergency, wetting, emulsification, etc) [11]. These are extremely important properties to investigate for the use of saponins as surfactants. 


\subsection{Micellization behavior and Reduction of Surface Tension}

In an aqueous solution, the surfactant molecules exhibit interesting behavior due to its amphiphilic structure. At low surfactant concentration, they tend to accumulate on the surface with the hydrophilic head oriented towards and hydrophobic head away from water molecules [44]. This phenomenon enhances surface activity and reduces the surface tension of water. The surfactant molecules remain unassociated up to a threshold concentration called critical micelle concentration (CMC). Above CMC, the excess surfactant molecules aggregate together to form a cluster called micelles. CMC is the saturation point at which the surfactant-containing aqueous solution acquires lowest stable surface tension value [45]. There is no substantial change in surfactant adsorption at the surface once micelles have formed. So, any further increase in surfactant concentration has no effect on surface tension; it just contributes to micelle formation [46]. Saponins, due to their amphiphilic nature, exhibit surface active properties like any other surfactants in aqueous solution. It also forms micelle above CMC [47] and reduce the surface tension of water accordingly [26].

$\mathrm{CMC}$ is an important physical parameter to determine surface active properties of surfactants. At CMC, various measurable physicochemical properties (such as electrical conductivity, surface tension, light scattering, refractivie index, etc.) of the surfactant solution show abrupt change due to which a sharp break point is obtained in the curve when plotted against the surfactant concentration or its logarithm in case of surface tension. The intersection point between the two fitted straight lines of the pre-CMC and post-CMC data determines the CMC value [11]. This feature has been extensively used in the experimental determination of the CMC of a surfactant solution [42]. The CMC of some saponin rich plant extracts have also been investigated by various methods. However, the CMC and reduced surface tension values at given saponin concentration of some saponin rich solution obtained by tensiometric methods are reported in Table 3 . For a comparative discussion, the CMC values along with the reduced surface tension values of some synthetic surfactants mostly used in commercial formulations are also reported in Table 4 .

Table 3: CMC and reduced surface tension values of aqueous saponin solutions extracted from some plants

\begin{tabular}{|c|c|c|c|c|c|}
\hline Saponin sources & Parts used & $\begin{array}{l}\text { CMC } \\
(\mathrm{g} / \mathrm{cc})\end{array}$ & $\begin{array}{l}\text { Reduced Surface } \\
\text { tension }(\mathrm{mN} / \mathrm{m}) \quad / \\
{[\text { Saponin }](\mathrm{g} / \mathrm{cc})}\end{array}$ & $\begin{array}{l}\text { Temperature } \\
\left({ }^{\circ} \mathrm{C}\right)\end{array}$ & References \\
\hline \multirow[t]{3}{*}{ Acacia concinna } & Pods & $7.00 \times 10^{-2}$ & $\approx 32.5 / 1.00 \times 10^{-2}$ & $20 \pm 2$ & {$[46]$} \\
\hline & Pods & NA & $35.6 \pm 0.2 / 1.00 \times 10^{-2}$ & 25 & [29] \\
\hline & Pericarp & $4.6552 \times 10^{-2}$ & NA & $\mathrm{NA}$ & {$[48]$} \\
\hline Agave sislana & & $6.84 \times 10^{-4}$ & $\begin{array}{l}(33.57-45.13) /(1.5- \\
4.5) \times 10^{-4}\end{array}$ & 25 & {$[36]$} \\
\hline \multirow[t]{2}{*}{ Albizia procera } & Leaves & $7.00 \times 10^{-3}$ & $\approx 43.75 / 1.00 \times 10^{-2}$ & $20 \pm 2$ & {$[46]$} \\
\hline & & NA & $46.6 \pm 0.2 / 6.0 \times 10^{-3}$ & 25 & [29] \\
\hline Bellis perennis & Flowers & $7.60 \times 10^{-5}$ & $36.8 / 7.60 \times 10^{-5}$ & 20 & [11] \\
\hline
\end{tabular}




\begin{tabular}{|c|c|c|c|c|c|}
\hline Betula pendula & Leaves & $2.4 \times 10^{-4}$ & $45.7 / 2.4 \times 10^{-4}$ & 20 & {$[11]$} \\
\hline Camellia oleifera & Seeds & NA & $50 / 5 \times 10^{-3}$ & NA & [49] \\
\hline Equisetum arvense & Haulm & $3.30 \times 10^{-5}$ & $37.9 / 3.30 \times 10^{-5}$ & 20 & {$[11]$} \\
\hline Genipa americana & Fruits & $6.50 \times 10^{-4}$ & $31.39 \pm 0.15$ & $25 \pm 1$ & {$[50]$} \\
\hline Hedera algeriensis & Leaves & $5.00 \times 10^{-4}$ & 40 & 20 & {$[51]$} \\
\hline Ilex paraguariensis & Fruits & $1.4946 \times 10^{-1}$ & 52.8 & $20 \pm 2$ & [40] \\
\hline Juglans regia & Bark & $8.80 \times 10^{-3}$ & $\approx 45.00 / 1.00 \times 10^{-2}$ & $20 \pm 2$ & [46] \\
\hline Panax ginseng & NA & $6.27 \times 10^{-4}$ & NA & 25 & {$[36]$} \\
\hline Quillaja saponaria & & $2.84 \times 10^{-4}$ & NA & 25 & {$[36]$} \\
\hline Tamarindus indica & Fruits & $8.70 \times 10^{-4}$ & $30.02 \pm 0.17$ & $25 \pm 1$ & {$[50]$} \\
\hline Sapindus laurifolia & Fruits & $1.70 \times 10^{-2}$ & 38.00 & NA & {$[52]$} \\
\hline \multirow[t]{3}{*}{ Sapindus mukorossi } & \multirow[t]{2}{*}{ Pods } & $7.50 \times 10^{-3}$ & $\approx 35.00 / 1.00 \times 10^{-2}$ & $20 \pm 2$ & [46] \\
\hline & & $7.50 \times 10^{-3}$ & $35.30 / 9.50 \times 10^{-2}$ & NA & {$[4]$} \\
\hline & Pericarp & $4.50 \times 10^{-3}$ & $\approx 39 / 4.50 \times 10^{-3}$ & 25 & [15] \\
\hline $\begin{array}{l}\text { Verbascum densiflo- } \\
\text { rum }\end{array}$ & Flowers & $3.55 \times 10^{-4}$ & $41.5 / 3.55 \times 10^{-4}$ & 20 & {$[11]$} \\
\hline \multirow[t]{2}{*}{ Zephyranthes cainata } & \multirow[t]{2}{*}{ Bulbs } & $6.40 \times 10^{-4}$ & $\approx 41.25 / 1.00 \times 10^{-2}$ & $20 \pm 2$ & {$[46]$} \\
\hline & & $6.40 \times 10^{-4}$ & $40.76 / 2.05 \times 10^{-2}$ & NA & {$[4]$} \\
\hline Ziziphus joazeiro & Barks & $1.064 \times 10^{-3}$ & $\begin{array}{l}(33.94-46.52) /(0.8- \\
5.5) \times 10^{-4}\end{array}$ & 25 & {$[36]$} \\
\hline
\end{tabular}


Table 4: CMC and reduced surface tension values of some synthetic surfactants in aqueous media

\begin{tabular}{|l|l|l|l|}
\hline Surfactant/ Nature & CMC $(\mathrm{g} / \mathrm{cc})$ & $\begin{array}{l}\text { Surface tension } \\
\text { at CMC }(\mathbf{m N} / \mathbf{m})\end{array}$ & $\begin{array}{l}\text { Temperature } \\
\left({ }^{\circ} \mathbf{C}\right)\end{array}$ \\
\hline $\begin{array}{l}\text { Cetyl trimethyl ammonium } \\
\text { bromide [CTAB]/ Cationic } \\
\mathrm{I} \\
\mathrm{t}\end{array}$ & $1.131 \times 10^{-3}[15]$ & $\mathrm{NA}$ & 25 \\
\cline { 2 - 4 } & $3.53 \times 10^{-1}[53]$ & $33.4[53]$ & 25 \\
\hline $\begin{array}{l}\text { Sodium Lauryl Sulphate/ } \\
\text { Anionic }\end{array}$ & $2.004 \times 10^{-3}[11]$ & $39.2[11]$ & 20 \\
\hline Tween 80/ Non-ionic & $4.42 \times 10^{-5}[11]$ & $44.4[11]$ & 20 \\
\hline $\begin{array}{c}\text { Triton X100/ Non-ionic } \\
\mathrm{C} \\
\mathrm{e}\end{array}$ & $1.30 \times 10^{-3}[15]$ & $\mathrm{NA}$ & 25 \\
\cline { 2 - 4 } & $1.8763 \times 10^{-1}[54]$ & $34.6[54]$ & 25 \\
\hline
\end{tabular}

$\mathrm{r}$ from Table 3 that CMC of saponins differ depending upon its source. These variations arise due to the differences in the chemical and molecular structures of saponins. Depending on the source, there is change in the hydrophobicity of the molecules and the sugar chains attached to it which affect the CMC values. In addition, it is also greatly influenced by the methods of saponin extractions and hence results from different methods differ for the same plant. Most of the saponin extracts tabulated in Table 3 showed CMC values lower than that of the synthetic surfactants (Table 4) which is of great importance. In general, the CMC values for saponins are one or two orders of magnitude less than that for the synthetic ones. It is reported that an effective surfactant can reduce the surface tension of water significantly from $72 \mathrm{mN} / \mathrm{m}$ to $32-37 \mathrm{mN} / \mathrm{m}$ [4] [11]. Most saponins extracts reported in Table 3 reduced surface tension to this extent which signifies good surface activity. In other words, this has the effect of reducing the surface tension of water causing it to foam [2]. Even at low concentration, saponins are able to reduce the surface tension and improve the foamability of aqueous solutions [40]. Formation of micelles in aqueous solution and reduction of surface tension are the characteristic features of any surfactants, responsible for its versatile industrial applications such as detergent, foaming agents, emulsifier, solubilizer, etc [11] which are discussed briefly in the later sections.

\subsection{Saponins as Cleaning and Wetting agents}

Surfactants possess ability to clean dirt, grime, and grease from the substrate [4]. As a result, it is added as a cleaning agent to a variety of household detergents and personal care products. Such agent facilitates the removal of dirt from the surface being cleaned that is otherwise insoluble in water. Cleaning action of a surfactant is associated with their abilities to reduce surface tension and form micelles in aqueous media [55]. Above CMC, the micellar aggregates remain suspended in water with the hydrophilic head portions forming outer shell and the hydrophobic tails forming the core of the micelles. The hydrophobic dirt and oil are trapped within the core by these micellar aggregates and solubilized which can then be readily washed away by water [56]. Cleaning efficiency of a surfactant is governed by its ability to wet the surface to be cleaned [4]. Wetting is a complex phenomenon associated with the adsorption of the surfactant at the solid liquid interface which leads to the decrease in the interfacial tension and enhances the wetting behavior. The application of surfactants as wetting agents finds application in the removal of soil, dye, lubrication and printing by washing and hence has increased commercial interest. Further, they also find application for controlling the spreading of drops in solid surfaces for industrial and medical applications [57]. Saponins as a substitute to the conventional surfactants have been routinely investigated for their cleaning and wetting abilities. Chen et al. (2010) reported moderate detergency of Camellia oleifera saponins compared to S. mukorossi crude saponins, SLS, and Tween 80 [3]. Pradhan et al. (2014) reported comparable cleaning efficiency of Acacia concinna saponins to that of Johnson's Baby shampoo while Albizia procera saponins lower efficiency. Similar results were obtained for their wetting ability also [58]. In another investigation, Pradhan et al. (2017) reported similar trend in cleaning abilities of natural 
surfactants Sapindus mukorossi (Ritha) and Zephyranthes carinata and synthetic surfactant, Henko. Ritha and Henko showed greater cleaning abilities at high concentration while Pyagi Phool was efficient at lower concentration Futher, least wetting time was reported for Henko, followed by Ritha which indicated good wetting by Ritha [4]. However, Rekiel et al. (2020) reported poor wetting ability of Saponaria officinalis saponins [59].

\subsection{Saponins as foaming agents and stabilizers}

Foaming is an important characteristic of a surfactant solution [60]. Foaming occurs when surfactant molecules partially occupy the liquid surface. In this process, spherical liquid films come out of the surface in the form of foams from areas unoccupied by the surfactant, and thus, having higher surface tension. Foam production, which is usually a property desired by consumers, has, however, very little to do with the surfactant's cleaning capabilities. Because of their large specific surface area, low specific weight, and ability to create a variety of mechanical properties ranging from liquid to solid, foams are particularly desirable for biomedical and personal care applications [52]. In addition to the rapid foam formation, stable and a satisfactory foaming level is necessary. So, commercial formulations frequently incorporate hazardous alkanol amide foam stabilizers. As a result, substitute goods that do not include alkanol amide are required. Most saponins are water soluble and exhibit foaming properties in aqueous solution [47]. Monodesmosidic saponins (with one sugar unit) have been reported to exhibit the best foaming characteristics than bidesmosidic saponins or tridesmosidic saponins (with two or three sugar units). Foaming property has been used for the qualitative analysis of saponins in plant extracts. The height and persistence of the froth formed when shaken with distilled water in a test tube determine its presence [32]. In addition to producing the proper amount of foam, saponins are reported to produce a stable foam [61]. And hence donot require additional stabilizers [30]. The excellent surface activity and foaming properties of saponin makes it viable candidate for the development of novel stable foams for biomedical purposes. Foaming strength of a surfactant is measured in terms of its foaming ability. It is determined as the height of the foam determined immediately after foam generation. Foam stability is the measure of the durability of the foam [62]. It is expressed in terms of R5 parameter defined as as the ratio of the foam height after $5 \mathrm{~min}$ to that measured in the first stage. Canto et al. (2010) reported abundant and persistant foaming ability of Ilex paraguariensis saponins. Futher they also reported diminshed foming ability of saponins in the presence of electrolytes [40], thereby concluding significant effect of additives on foaming ability of saponins. As per the investigation by Tmáková et al. (2015) on the foaming ability of saponins extracted from various plants: B pendula (leaves), and $S$. mukorossi (pericarp) exhibitted good foaming ability while $V$. densiflorum (Flowers) showed minimum foaming against the synthetic surfactants SLS and Tween 80. Further, all the saponin extract reported R5 values more than 50\% representing good foaming stability comparable to the synthetic ones [11]. Pradhan et al. (2017) also reported high foaming ability of S. mukorossi with R5 value more than 60\%[4]. Saxena et al., (2018) studied foaming properties of Sapindus laurifolius (fruit) and reported formation of stable foams at highsaponin concentration [63].

\subsection{Saponins as emulsifiers}

Surfactants are commonly employed for creating and stabilizing emulsion-based products in food, pharmaceuticals, cosmetics, and other industries because of their emulsification properties [60]. Surfactants' amphiphilic nature allows them to adsorb into oil-water interfaces during homogenization, lowering interfacial tension and resulting in stable emulsions. Natural emulsifiers, according to previous research, are capable of generating a good and stable emulsion. As a result of these research, saponins are now being used as surfactants in the production of oil-in-water emulsions. Tmáková et al. (2015) reported that S. mukorossi, V. densiflorum and E. arvense saponins showed better emulsification ability than synthetic surfactants ( SLS and Tween 80) [11] Pradhan et al. (2017) also reported better emulsionsification of natural surfactants extracted from Sapindus mukorossi Gaertn and Zephyranthes carinata Herbert over the synthetic formulation Henko [4]. De Almeida et al. 2017 explored the physicochemical properties of Genipa americana L. and Tamarindus indica $L$. fruits saponins and reported good surface activity and emulsifying property for their potential application in oil removal [50]. Saxena et al., (2018) studied emulsification properties of Sapindus laurifolius (fruit) and reported the formation of emulsion with maximum stability near CMC [63]. Sabri et al. (2020) studied physicochemical 
properties of triterpene saponins extracted from Hedera helix Algeriensis for the formulation of oil-in water emulsions. The study revealed better stability of emulsions in the presence of a sufficient quantity of saponins [51]. The surfactant property of saponins find applicationa as emulsifiers in beverages. Saponins derived from quilaja is used in beverage emulsion [64], as model coffee creamers [64] and as effective food encapsulation in forming edible vitamin E [64].

\subsection{Saponins as solubilizers}

Surfactants can solubilize organic non-polar compounds (such as petroleum, dye, soil, etc) in their hydrophobic core [55]. Conventional surfactants have been utilized in the various industrial and environmental processes as solubilizing agents e.g., micellar enhance ultrafiltration (MEUF) processes for removal of pollutants from the aqueous system [65-67], surfactant enhance remediation (SER) for soil remediation [68,69], micellar enhanced oil recovery (MEOR) process for higher oil recovery [70], solubilization of hydrophobic dyes in dying as well as dye removal processes [71], solubilization of hydrophobic drugs [72], etc. However, with the increasing threat of the synthetic surfactants on the environment, saponins as a natural surfactant have attracted researchers' interest in these arenas as well. Some of which are reported here. Roy et al. (1997) investigated saponins obtrained from the fruit pericarp of Sapindus mukurossi for soil washing applications and were found comparable to that of typical commercial surfactants [73]. Chhetri et al. (2009) studied Sapindus mukurossi (pericarp) extract for enhanced oil recovery. The investigation reported that the extract significantly reduced the interfacial tension and presented its great potential for enhanced oil recovery [10]. Similarly, Samal et al. (2017) also reported positive results for the solubilization of dyes (methylene blue/ cationic and eosin yellow/ anionic) by the saponins extracted from the fruit pericarp of Sapindus mukurossi [74]. Vinarov et al. (2018) studied solubilisation of hydrophobic drugs by 13 different saponin extracts and found improved solubilisation of danazol and fenofibrate in the presence of Quillaja saponaria and Camellia oleifera than Brij-35 [75].

\subsection{Saponins in commercial formulations}

As the herbal extracts have been supposed to be good alternatives for the chemical preparations, various investigations have been carried out to develop personal cares products especially shampoo that are based on naturally derived ingredients. Some of which are reported here. Mainkar and Jolly in 2000 investigated the assessment of commercial herbal shampoos using surface tension, foaming test, wetting test, and other criteria. The findings of these tests provided insight into the criteria a laboratory-formulated shampoo should meet in order to be comparable to commercial shampoos [76]. In another investigation made in 2001, they attempted to formulate completely natural shampoo with saponins obtained from the pericarps of Sapindus mukorossi and alkylpolyglycoside as a major ingredient. The formulations so prepared presented detergency, surface tension, $\mathrm{pH}$ and other parameters comparable to that of commercial ones, implying the possibility of formutating completely natural shampoo which was otherwise considered a challenging task [77]. Aghel et al. conducted a study in 2007 with the goal of completely replacing harmful ingredients in shampoo formulations. Instead, they assessed the physicochemical, rheological, and organoleptic behaviors of saponins isolated from the roots of Acanthophyllum squarrosum as a substitute. The final formulation was found to be desirable, with great cleaning performance and steady foaming ability, and was proposed as a replacement for numerous hazardous surfactants and foaming agents [31]. Nizioł-Łukaszewska et al. (2018) performed assessment of three saponin containing plants (Glycyrrhiza glabra, Viola tricolor, and Solanum dulcamara) as multifunctional cosmetic materials. Addition of saponins to the bodywash gel formulations enhanced the rheological and foaming properties of the products and also contributed reduce skin irritation potential. The findings of this study provide rationale for classifying saponins as safe ingredients in cosmetic formulations [78]. Recently, Moghimipour et al. (2021) also formulated synthetic surfactant free shampoo, saponins from roots of Acanthophyllum squarrosum being the major ingredients. The resulting mixture likewise demonstrated good cleaning capabilities, had a $\mathrm{pH}$ value within an acceptable range, and was deemed suitable for usage [30]. 


\subsection{Other applications of saponins}

Apart from the potential surfactant application, saponins find a broad spectrum of potential applications ranging from pharmaceutical industry to food and cosmetics. The pharmaceutical applications can be attributed to their antimicrobial, antioxidant, anti-inflammatory, antidiabetic, anticancer, cholesterol lowering properties, and hemolytic activities that adds the immune response of the organisms $[80,81]$.

Antimicrobial activity of saponins from various plant sources against various bacterial and fungal strains are well documented. Quinoa saponins extracted from the husks of Chenopodium quinoa is reported to pose antibacterial property against Staphylococus aureu, S. epidermidis and B. cereus causing severe damage through bacterial cell wall degradation followed by disruptions of the cytoplasmic membrane and membrane proteins [81]. Similarly, antifungal activity of Ziziphus joazeiro (bark) saponins has been reported against Candida albicans and Aspergillus niger [36]. Antioxidant property of saponins from Camellia roots[82], and seed cakes [83] steroidal saponins from Agave sisalana and triterpenic saponins from Ziziphus joazeiro [36] have also been reported. Several other studies are focused on the antidiabetic property of saponins as well because of their ability to reduce the increased blood plasma glucose, e.g., saponins from Panax noto ginseng [82- 84] and Entada phaseoloides (seeds)[84-85]. Similarly, hypoglycemic and hypolipidemic activity of total saponins extracted from the stems of Stauntonia chinensis in diabetic mice opened up the possibility for its utilization in the treatment of type -2 diabetic [88].

Adjuvant potentials on immune response of mice against ova has been recorded for Astragalus membranaceus saponins by Yang et al. (2005) [89]. Sun (2006) and Verza et al. (2012) also revealed that saponin fractions derived from the seeds of Chenopodium quinoa (seeds) [90] and Bupleurum chinense (roots) [91] boosted the hemolytic activities and adjuvant potentials on immune responses of mice against ovalbumin. Several other studies on hemolytic activity with immunological adjuvant property of saponins have been reported from quilaja saponins [92], soya saponins [93], Japenese ginseng saponins [94]. Saponin enriched fraction from Silene vulgaris (Moench) Garcke, have been reported to pose in vitro hemolytic activity in sheep, although being less effective than that of Sapindus mukorossi and Chlorophytum borivilianum [95].

Recently, anticancer activity of both triterpenoid and steroid saponins are gaining much attention. The in vitro and in vivo anticancer activities exhibited by saponins (ginsenosides and saikosaponins) and (dioscin, polyphyllin and timosaponin )include antiproliferation, anti-metastasis, anti-angiosgenesis reversa of multidrug resistance (MDR) and autophagy regulation actions, being brought about by induction of apoptosis, promotion of cell differentiation, immune- modulatory effects, bile acid-binding and amelioration of carcinogen induces cell proliferation [88]. The potential anticancer effect of ginsenosides have been extensively studied against leukemia [96,97], esophageal carcinoma [98], breast cancer [99,100], prostate cancer $[101,102]$ and many more. Saikosaponin has been reported to be effective against lung cancer [103], hepatoma and pancreatic cancer, prostate cancer [104], etc. Dioscin extracted form Polygonatum zanlanscianense (roots) is effective against breast cancer [105]. Anticancer potential of dioscin against leukemia has also been reported [106]. Polyphyllin isolated from Paris polyphylla (rhizome) inhibits proliferation of various cancer cells including human leukemia [104] and lungs carcinoma [107].

Because of their intense sweetness and bitterness, saponins are used as natural sweeteners in foods and herbal medicines. Sweetness of Licorice saponins synthesized from roots of Glycyrrhiza inflate, G. uralrnsis, G, glabra, G.aspera and G. uralensis finds its use in Chinese medicine [107]. Licorice also finds its application as flavoring agents in foods and medicine [64].

\section{Challenges and Future Perspectives}

Natural surfactants have gained popularity as a sustainable alternative to synthetic surfactants. It has been further supported by the growth of consumer demands and restrictive environmental legislation. This has encouraged manufacturers to develop more herbal products. However, at present, the choices are limited and most of the available product aesthetics include 
the conventional synthetic surfactants base with herbal ingredients added solely for marketing purposes rather than for their effectiveness. It is because developing commercial formulations completely based on natural raw materials is considered a challenging process. The challenge lies within the selection of material that can be rationally justified as natural and formulating them into products whose functionality equivalent to their synthetic counterparts. A more radical approach in popularizing natural surfactants would be required to change the consumer perception of herbal products, with emphasis on safety and efficacy. Formulators also must play an active role in educating the consumers about the potential hazardous consequences of synthetic goods and other chemical additions. Further the extraction and processing cost of the natural surfactants to the final product is comparatively expensive than the synthetic ones. As a result, although being safe and free of adverse effects, these products do not enjoy market popularity. Hence, another significant challenge to be overcome is the introduction of natural surfactants as low-cost alternatives.

\section{Conclusions}

With this review, we can conclude that saponins derived from plant sources can be a sustainable and eco-friendly alternative to synthetic surfactants. The utilization of natural surfactants helps in reducing the environmental pollutions caused by the extreme application of synthetic surfactants in diverse fields. So, future investigations should focus on identification of some more plant based natural surfactants.

Author Contributions: Conceptualization, S.R. and A.B.; methodology, S.R., A.B.; writing-original draft preparation, S.R., E.A.S., H.P.D., A.B.; writing-review and editing, S.R., A.K., H.P.D., A.B. All authors have read and agreed to the published version of the manuscript.

Funding: This research received no external funding.

Institutional Review Board Statement: Not applicable.

Informed Consent Statement: Not applicable.

Conflicts of Interest: The authors declare no conflict of interest.

\section{References}

1. Landrigan, P.J.; Fuller, R.; Acosta, N.J.R.; Adeyi, O.; Arnold, R.; Basu, N. (Nil); Baldé, A.B.; Bertollini, R.; Bose-O’Reilly, S.; Boufford, J.I.; et al. The Lancet Commission on pollution and health. Lancet 2018, 391, 462-512.

2. Kregiel, D.; Berlowska, J.; Witonska, I.; Antolak, H.; Proestos, C.; Babic, M.; Babic, L.; Zhang, B. Saponin-Based, Biological-Active Surfactants from Plants. In Application and Characterization of Surfactants; InTech, 2017.

3. Chen, Y.F.; Yang, C.H.; Chang, M.S.; Ciou, Y.P.; Huang, Y.C. Foam properties and detergent abilities of the saponins from Camellia oleifera. Int. J. Mol. Sci. 2010, 11, 4417-4425.

4. Pradhan, A.; Bhattacharyya, A. Quest for an eco-friendly alternative surfactant: Surface and foam characteristics of natural surfactants. J. Clean. Prod. 2017, 150, 127-134.

5. U, K.H. Natural surfactants. 2001, 148-159.

6. Negm, N.A.; El-Tabl, A.S.; Aiad, I.A.; Zakareya, K.; Moustafa, A.H. Synthesis, characterization, biodegradation and evaluation of the surface active properties of nonionic surfactants derived from Jatropha oil. J. Surfactants Deterg. 2013, 16, 857-863.

7. Jahan, K.; Balzer, S.; Mosto, P. Toxicity of nonionic surfactants. 110, 281-290.

8. Yuan, C.L.; Xu, Z.Z.; Fan, M.X.; Liu, H.Y.; Xie, Y.H.; Zhu, T. Study on characteristics and harm of surfactants. 2014, 6, 2233-2237.

9. Nkafamiya, I.; Honda, J.; Eneche, J.; Haruna, M. Extraction and Evaluation of a Saponin-base Surfactant from Cissus populnea Plant as an Emulsifying Agent. Asian J. Chem. Sci. 2018, 4, 1-7.

10. Chhetri, A.B.; Watts, K.C.; Rahman, M.S.; Islam, M.R. Soapnut extract as a natural surfactant for enhanced oil recovery. Energy Sources, Part A Recover. Util. Environ. Eff. 2009, 31, 1893-1903. 
11. Tmáková, L.; Sekretár, S.; Schmidt, Š. Plant-derived surfactants as an alternative to synthetic surfactants: Surface and antioxidant activities. Chem. Pap. 2015, 70, 188-196.

12. Wojtoń, P.; Szaniawska, M.; Hołysz, L.; Miller, R.; Szcześ, A. Surface activity of natural surfactants extracted from Sapindus mukorossi and Sapindus trifoliatus soapnuts. Colloids and Interfaces 2021, 5.

13. Garc, F.Y.; Allen, D.G.; Acosta, E.J. Surfactants from Waste Biomass. 2010.

14. Drahansky, M.; Paridah, M..; Moradbak, A.; Mohamed, A..; Owolabi, F. abdulwahab taiwo; Asniza, M.; Abdul Khalid, S.H. We are IntechOpen, the world 's leading publisher of Open Access books Built by scientists, for scientists TOP $1 \%$. Intech 2016, $i, 13$.

15. Balakrishnan, S.; Varughese, S.; Deshpande, A.P. Micellar characterisation of saponin from Sopindus mukorossi. Tenside, Surfactants, Deterg. 2006, 43, 262-268.

16. Dias, B.; Sales, D.; Weingart, D.; Alice, M.; Coelho, Z. Colloids and Surfaces A : Physicochemical and Engineering Aspects Functional properties of saponins from sisal ( Agave sisalana ) and juá ( Ziziphus joazeiro ): Critical micellar concentration , antioxidant and antimicrobial activities. Colloids Surfaces A Physicochem. Eng. Asp. 2013, 436, 736-743.

17. Wisetkomolmat, J.; Suppakittpaisarn, P.; Sommano, S.R. Detergent Plants of Northern Thailand : Potential Sources of Natural Saponins. 2019, 1-14.

18. Sparg, S.G.; Light, M.E.; Staden, J. Van Biological activities and distribution of plant saponins. 2004, 94, $219-243$.

19. Fuchs, H.; Weng, A. Chemistry and pharmacology of saponins : special focus on cytotoxic properties. 2011, 19-29.

20. Vincken, J.; Heng, L.; Groot, A. De; Gruppen, H. Saponins , classification and occurrence in the plant kingdom. 2007, 68, 275-297.

21. Böttcher, S.; Drusch, S. Saponins - Self-assembly and behavior at aqueous interfaces. Adv. Colloid Interface Sci. 2017, 243, 105-113.

22. Ruano, P.; Delgado, L.L.; Picco, S.; Villegas, L.; Tonelli, F.; Merlo, M.; Rigau, J.; Diaz, D.; Masuelli, M. We are IntechOpen , the world' s leading publisher of Open Access books Built by scientists, for scientists TOP $1 \%$. Intech 2016, 13.

23. Moghimipour, E.; Handali, S. Saponin : Properties , Methods of Evaluation and Applications. 2015, 5, $207-220$.

24. Majinda, R.R.T. Chapter 16 Extraction and Isolation of Saponins. 2015.

25. Chaieb, I. Saponins as Insecticides : a Review. 2010, 5.

26. Böttger, S.; Hofmann, K.; Melzig, M.F. Bioorganic \& Medicinal Chemistry Saponins can perturb biologic membranes and reduce the surface tension of aqueous solutions : A correlation? 2012, 20, 2822-2828.

27. Access, O. We are IntechOpen, the world 's leading publisher of Open Access books Built by scientists, for scientists TOP 1 $\%$.

28. Taylor, P. Saponins : Properties, Applications and Processing Saponins : Properties, Applications. $2007,37-41$.

29. Pradhan, A.; Bhattacharyya, A. Shampoos Then and Now : Synthetic versus. 2014, 30, 59-76.

30. Moghimipour, E.; Jasemnezhad, M.; Mohammad Soleymani, S.; Salimi, A. Preparation and evaluation of a free surfactant herbal shampoo with Acanthophyllum Squarrosum Saponins. J. Cosmet. Dermatol. 2021, 20, 181-187.

31. Aghel, N.; Moghimipour, E.; Raies, A. Formulation of a Herbal Shampoo using Total Saponins of Acanthophyllum squarrosum. Iran. J. Pharm. Res. 2007, 6, 167-172.

32. Oleszek, W.; Hamed, A. Saponin-Based Surfactants. 2010.

33. Oleszek, W.; Bialy, Z. Chromatographic determination of plant saponins - An update (2002 - 2005 ). 2006, 1112, 78-91.

34. Sharma, O.P.; Kumar, N.; Singh, B.; Bhat, T.K. An improved method for thin layer chromatographic analysis of saponins. Food Chem. 2012, 132, 671-674.

35. Pérez, A.J.; Calle, J.M.; Simonet, A.M.; Guerra, J.O.; Stochmal, A.; Macías, F.A. Phytochemistry Bioactive steroidal saponins from Agave offoyana flowers. 2013, 95, 298-307.

36. Ribeiro, B.D.; Alviano, D.S.; Barreto, D.W.; Coelho, M.A.Z. Functional properties of saponins from sisal (Agave sisalana) and juá (Ziziphus joazeiro): Critical micellar concentration, antioxidant and antimicrobial activities. Colloids Surfaces $A$

Physicochem. Eng. Asp. 2013, 436, 736-743. 
37. Sharma, P.; Saini, M.K.; Prasad, J.; Gour, V.S. Evaluation of Robustness of the Biosurfactant Derived from Balanites aegyptiaca (L.) Del. J. Surfactants Deterg. 2019, 22, 403-408.

38. Yu, X.L.; He, Y. Tea saponins: Effective natural surfactants beneficial for soil remediation, from preparation to application. RSC Adv. 2018, 8, 24312-24321.

39. Savage, G.P. Savage2003. 1993, 5095-5098.

40. Canto, G.S. Do; Treter, J.; Yang, S.; Borré, G.L.; Peixoto, M.P.G.; Ortega, G.G. Evaluation of foam properties of saponin from Ilex paraguariensis A. St. Hil. (Aquifoliaceae) fruits. Brazilian J. Pharm. Sci. 2010, 46, 237-243.

41. Cheok, C.Y.; Abdel, H.; Salman, K.; Sulaiman, R. Extraction and quanti fi cation of saponins : A review. 2014, 59, 16-40.

42. Rosen, M.J.; Kunjappu, J.T. PHENOMENA SURFACTANTS AND PHENOMENA FOURTH EDITION; ISBN 9780470541944.

43. Schramm, L.L.; Stasiuk, E.N.; Marangoni, D.G. Surfactants and their applications. Annu. Reports Prog. Chem. - Sect. C 2003, 99, 3-48.

44. Olkowska, E.; Ruman, M.; Polkowska, Z. Occurrence of surface active agents in the environment. J. Anal. Methods Chem. 2014, 2014.

45. Müller, L.E.; Schiedeck, G. Physical properties of botanical surfactants. Sci. Total Environ. 2018, 610-611, 1133-1137.

46. Pradhan, A.; Bhattacharyya, A. An Alternative Approach for Determining Critical Micelle Concentration : Dispersion of Ink in Foam. 2018.

47. Negi, J.S.; Negi, P.S.; Pant, G.J.; Rawat, M.; Negi, S.K. Naturally occurring saponins: Chemistry and biology. J. Poisonous Med. Plant Res. 2013, 1, 1-6.

48. Muhammad, M.T.; Khan, M.N. Eco-friendly, biodegradable natural surfactant (Acacia Concinna): An alternative to the synthetic surfactants. J. Clean. Prod. 2018, 188, 678-685.

49. Chen, Y.; Yang, C.; Chang, M.; Ciou, Y.; Huang, Y. Foam Properties and Detergent Abilities of the Saponins from Camellia oleifera. 2010, 4417-4425.

50. De Almeida, F.C.G.; Da Rocha E Silva, N.M.P.; Meira, H.M.; Jara, A.M.T.; De Luna, J.M.; Sarubbo, L.A. Physico-chemical properties of the biosurfactant obtained from fruit extract of Genipa americana L. and Tamarindus indica L. and its application in oil removal. Chem. Eng. Trans. 2017, 57, 1549-1554.

51. Sabri, N.; Moulai-Mostefa, N. Formulation and characterization of oil-in-water emulsions stabilized by saponins extracted from Hedera Helix Algeriensis using response surface method. Biointerface Res. Appl. Chem. 2020, 10, 6282-6292.

52. Anuragi, J.L.; Pradesh, R.M.; Pradesh, M.; Pradesh, M. Separation of Saponins from Sapindus laurifolia ( L .). 2017,2 , 21-24.

53. Shah, S.K.; Chatterjee, S.K.; Bhattarai, A. Micellization of cationic surfactants in alcohol - water mixed solvent media. J. Mol. Liq. 2016, 222, 906-914.

54. Zhang, S.; Gao, Y.; Dong, B.; Zheng, L. Colloids and Surfaces A : Physicochemical and Engineering Aspects Interaction between the added long-chain ionic liquid 1-dodecyl-3-methylimidazolium tetrafluoroborate and Triton X-100 in aqueous solutions. Colloids Surfaces A Physicochem. Eng. Asp. 2010, 372, 182-189.

55. Rakowska, J.; Radwan, K.; Porycka, B.; Prochaska, K. Experimental study on surface activity of surfactants on their ability to cleaning oil contaminations. J. Clean. Prod. 2017, 144, 437-447.

56. Yakimchuk, O.D.; Kotomin, A.A.; Petel'Skii, M.B.; Naumov, V.N. Cleaning action and surfactant properties of alkyl glucosides. Russ. J. Appl. Chem. 2004, 77, 2001-2005.

57. Lee, K.S.; Ivanova, N.; Starov, V.M.; Hilal, N.; Dutschk, V. Kinetics of wetting and spreading by aqueous surfactant solutions. Adv. Colloid Interface Sci. 2008, 144, 54-65.

58. Pradhan, A.; Bhattacharyya, A. Shampoos then and now : synthetic versus natural. J. Surf. Sci. Technol. 2014, $30,59-76$.

59. Rekiel, E.; Smułek, W.; Zdziennicka, A.; Kaczorek, E.; Jańczuk, B. Wetting properties of Saponaria officinalis saponins. Colloids Surfaces A Physicochem. Eng. Asp. 2020, 584.

60. Koczo, K.; Racz, G. Foaming properties of surfactant solutions. Colloids and surfaces 1991, 56, 59-82.

61. Sari, K.; Setiawan, I.K.I. Utilization of natural surfactants from saponin compound of coconut leaf waste (Cocos Nucifera L.) as an environmentally friendly liquids detergent. J. Phys. Conf. Ser. 2019, 1402. 
62. Wang, H.; Guo, W.; Zheng, C.; Wang, D.; Zhan, H. Effect of Temperature on Foaming Ability and Foam Stability of Typical Surfactants Used for Foaming Agent. J. Surfactants Deterg. 2017, 20, 615-622.

63. Saxena, N.; Pal, N.; Ojha, K.; Dey, S.; Mandal, A. Synthesis, characterization, physical and thermodynamic properties of a novel anionic surfactant derived from: Sapindus laurifolius. RSC Adv. 2018, 8, 24485-24499.

64. Tao, W.; Duan, J.; Zhao, R.; Li, X.; Yan, H.; Li, J.; Guo, S. Comparison of three officinal Chinese pharmacopoeia species of Glycyrrhiza based on separation and quantification of triterpene saponins and chemometrics analysis. Food Chem. 2013, 141, 1681-1689.

65. Das, C.; DasGupta, S.; De, S. Prediction of permeate flux and counterion binding during cross-flow micellar-enhanced ultrafiltration. Colloids Surfaces A Physicochem. Eng. Asp. 2008, 318, 125-133.

66. Purkait, M.K.; DasGupta, S.; De, S. Removal of dye from wastewater using micellar-enhanced ultrafiltration and recovery of surfactant. Sep. Purif. Technol. 2004, 37, 81-92.

67. Gzara, L.; Dhahbi, M. Removal of chromate anions by micellar-enhanced ultrafiltration using cationic surfactants. Desalination 2001, 137, 241-250.

68. Pennell, K.D.; Jin, M.; Abriola, L.M.; Pope, G.A. Surfactant enhanced remediation of soil columns contaminated by residual tetrachloroethylene. J. Contam. Hydrol. 1994, 16, 35-53.

69. Mulligan, C.N.; Yong, R.N.; Gibbs, B.F. Surfactant-enhanced remediation of contaminated soil: A review. Eng. Geol. 2001, 60, $371-380$.

70. Bordoloi, N.K.; Konwar, B.K. Microbial surfactant-enhanced mineral oil recovery under laboratory conditions. Colloids Surfaces B Biointerfaces 2008, 63, 73-82.

71. Pandit, P.; Basu, S. Removal of Ionic Dyes from Water by Solvent Extraction Using Reverse Micelles. Environ. Sci. Technol. 2004, 38, 2435-2442.

72. Tehrani-Bagha, A.R.; Holmberg, K. Solubilization of hydrophobic dyes in surfactant solutions. Materials (Basel). 2013, 6, 580-608.

73. Roy, D.; Kommalapati, R.R.; Mandava, S.S.; Valsaraj, K.T.; Constant, W.D. Sail washing potential of a natural surfactant. Environ. Sci. Technol. 1997, 31, 670-675.

74. Samal, K.; Das, C.; Mohanty, K. Eco-friendly biosurfactant saponin for the solubilization of cationic and anionic dyes in aqueous system. Dye. Pigment. 2017, 140, 100-108.

75. Vinarov, Z.; Radeva, D.; Katev, V.; Tcholakova, S.; Denkov, N. Solubilisation of hydrophobic drugs by saponins. Indian J. Pharm. Sci. 2018, 80, 709-718.

76. Mainkar, A.R.; Jolly, C.I. Evaluation of commercial herbal shampoos. Int. J. Cosmet. Sci. 2000, $22,385-391$.

77. Mainkar, A.R.; Jolly, C.I. Formulation of natural shampoos. Int. J. Cosmet. Sci. 2001, 23, 59-62.

78. Nizioł-Łukaszewska, Z.; Bujak, T. Saponins as Natural Raw Materials for Increasing the Safety of Bodywash Cosmetic Use. J. Surfactants Deterg. 2018, 21, 767-776.

79. Guclu-Ustundag, Ö.; Mazza, G. Saponins: Properties, applications and processing. Crit. Rev. Food Sci. Nutr. 2007, 47, 231-258.

80. Cheok, C.Y.; Salman, H.A.K.; Sulaiman, R. Extraction and quantification of saponins: A review. Food Res. Int. 2014, 59, 16-40.

81. Dong, S.; Yang, X.; Zhao, L.; Zhang, F.; Hou, Z.; Xue, P. Industrial Crops \& Products Antibacterial activity and mechanism of action saponins from Chenopodium quinoa Willd. husks against foodborne pathogenic bacteria. Ind. Crop. Prod. 2020, 149, 112350.

82. Sur, P.; Chaudhuri, T.; Vedasiromoni, J.R.; Gomes, A.; Ganguly, D.K.; Wiley, J. Antiinflammatory and Antioxidant Property of Saponins of Tea [ Camellia sinensis ( L ) O . Kuntze ] Root Extract. 2001, 176, 174-176.

83. Hu, J.; Nie, S.; Huang, D.; Li, C.; Xie, M. Original article Extraction of saponin from Camellia oleifera cake and evaluation of its antioxidant activity. 2012,1-12.

84. Chen, Z.; Li, J.; Liu, J.; Zhao, Y.; Zhang, P.; Zhang, M.; Zhang, L. Saponins Isolated from the Root of Panax notoginseng Showed Significant Anti-Diabetic Effects in KK-Ay Mice. 2008, 36, 939-951.

85. Yang, C.; Wang, J.; Zhao, Y.; Shen, L.; Jiang, X.; Xie, Z. Anti-diabetic effects of Panax notoginseng saponins and its major anti-hyperglycemic components. 2010, 130, 231-236. 

EXTRACTS OF ENTADA PHASEOLOIDES ...

87. Zheng, T.; Shu, G.; Yang, Z.; Mo, S.; Zhao, Y.; Mei, Z. Antidiabetic effect of total saponins from Entada phaseoloides (L.) Merr. in type 2 diabetic rats. J. Ethnopharmacol. 2012, 139, 814-821.

88. $\mathrm{Xu}$, J.; Wang, S.; Feng, T.; Chen, Y.; Yang, G. Hypoglycemic and hypolipidemic effects of total saponins from Stauntonia chinensis in diabetic $\mathrm{db} / \mathrm{db}$ mice. 2018.

89. Yang, Z.; Sun, H.; Fang, W. Haemolytic activities and adjuvant effect of Astragalus membranaceus saponins ( AMS ) on the immune responses to ovalbumin in mice. 2005, 23, 5196-5203.

90. Verza, S.G.; Silveira, F.; Cibulski, S.; Kaiser, S.; Ferreira, F.; Gosmann, G.; Roehe, P.M.; Ortega, G.G. Immunoadjuvant Activity, Toxicity Assays, and Determination by UPLC/Q-TOF-MS of Triterpenic Saponins from Chenopodium quinoa Seeds. 2012.

91. Sun, H. Haemolytic activities and adjuvant effect of Bupleurum chinense saponins on the immune responses to ovalbumin in mice. 2006, 24, 1324-1331.

92. Fleck, J.D.; Kauffmann, C.; Spilki, F.; Lencina, C.L.; Roehe, P.M.; Gosmann, G. Adjuvant activity of Quillaja brasiliensis saponins on the immune responses to bovine herpesvirus type 1 in mice. 2006, 24, 7129-7134.

93. Qiao, N.; Liu, Q.; Meng, H.; Zhao, D. International Immunopharmacology Haemolytic activity and adjuvant effect of soyasaponins and some of their derivatives on the immune responses to ovalbumin in mice. Int. Immunopharmacol. 2014, 18, 333-339.

94. Sun, Y.; Tong, H.; Li, M.; Li, Y.; Guan, S.; Liu, J. Immunological adjuvant effect of Japanese ginseng saponins ( JGS ) on specific antibody and cellular response to ovalbumin and its haemolytic activities. 2008, 26, 5911-5917.

95. Singh, R.; Sharma, R.; Mal, G.; Varshney, R. A comparative analysis of saponin-enriched fraction from Silene vulgaris ( Moench ) Garcke, Sapindus mukorossi ( Gaertn ) and Chlorophytum borivilianum ( Santapau and Fernandes ): an in vitro hemolytic and cytotoxicity evaluation. Anim. Biotechnol. 2020, 0, 1-7.

96. Kitts, D.D.; Popovich, D.G.; Hu, C. Characterizing the mechanism for ginsenoside- induced cytotoxicity in cultured leukemia ( THP-1 ). 2007, 1183, 1173-1183.

97. Huang, J.; Peng, K.; Wang, L.; Wen, B.; Zhou, L.; Luo, T.; Su, M.; Li, J.; Luo, Z. Ginsenoside Rh2 inhibits proliferation and induces apoptosis in human leukemia cells via TNF- $\alpha$ signaling pathway. 2016, 2, 1-6.

98. Chang, L.; Huo, B.; Lv, Y.; Wang, Y.; Liu, W.E.I. Ginsenoside Rg3 enhances the inhibitory effects of chemotherapy on esophageal squamous cell carcinoma in mice. 2014, 1043-1046.

99. Choi, S.; Kim, T.W.; Singh, S. V Ginsenoside Rh2-mediated G 1 Phase Cell Cycle Arrest in Human Breast Cancer Cells Is Caused by p15 Ink4B and p27 Kip1 -dependent Inhibition of Cyclin-dependent Kinases. 2009, 26, 2280-2288.

100. Choi, S.; Oh, J.; Kim, S. Cellular Biochemistry. 2011, 340, 330-340.

101. Kim, H.; Lee, E.; Ko, S.; Chop, K.; Park, J.; Im, D. Effects of Ginsenosides Rg3 and Rh2 on the Proliferation of Prostate Cancer Cells. 2004, 27, 429-435.

102. Musende, A.G.; Eberding, Æ.A.; Wood, Æ.C.; Adomat, Æ.H.; Fazli, L.; William, Æ.A.H.Æ.; Marcel, J.Æ. Pre-clinical evaluation of Rh2 in PC-3 human xenograft model for prostate cancer in vivo : formulation, pharmacokinetics , biodistribution and efficacy. 2009, 1085-1095.

103. Hsu, Y.; Kuo, P.; Lin, C. The proliferative inhibition and apoptotic mechanism of Saikosaponin D in human non-small cell lung cancer A549 cells. 2004, 75, 1231-1242.

104. Yao, M.I.N.; Yang, J.; Cao, L.; Zhang, L.; Qu, S.; Gao, H. Saikosaponin - d inhibits proliferation of DU145 human prostate cancer cells by inducing apoptosis and arresting the cell cycle at G0 / G1 phase. 2014, 365-372.

105. Lee, E.K.J.J.Y.; Kim, E.S.I.S.J.; Mcl-, A.I.F.Á. Dioscin induces caspase-independent apoptosis through activation of apoptosis-inducing factor in breast cancer cells. 2014, 1165-1175.

106. Iu, M.L.; Ang, Z.W.; Yong, J.U.; Hou, J.Z.; Ang, Y.W.; Ong, R.N.W.; Kong, H.; Kong, H. The Mitotic-Arresting and Apoptosis-Inducing Effects of Diosgenyl Saponins on Human Leukemia Cell Lines. 2004, 27, 1059-1065. 
107. Siu, F.; Cheung, Y.; Lok, C.; Yan, K.; Yang, Z.; Yang, M.; Xu, S.; Ko, B.C.; He, Q.; Che, C. Proteomic and transcriptomic study on the action of a cytotoxic saponin ( Polyphyllin D ): Induction of endoplasmic reticulum stress and mitochondriamediated apoptotic pathways. 2008, 3105-3117. 